\title{
IMPLEMENTASI KEBIJAKAN HYGIENE SANITASI PENGELOLAAN MAKANAN DAN MINUMAN PADA FASILITAS UMUMDI KOTA PALANGKA RAYA
}

\author{
Implementation of Sanitation Hygiene Policy for Food and Beverage Management in Public Facilities \\ in the City of Palangka Raya
}

\section{Muhaimin Noor* \\ Dwi Rochani Fatmiasih}

Universitas Muhammadiyah

Palangkaraya, Palangka Raya, Central

Kalimantan, Indonesia

email:

muhaimin.noor@umpalangkaraya.ac.id

Kata Kunci:

Impelementasi

Kebijakan

Pengelolaan

Sanitasi

\section{Keywords:}

Implementation

Policy

Management

Sanitation

\section{Accepted}

June 2017

\section{Published}

Oktober 2017

\begin{abstract}
Abstrak
Penelitian ini bertujuan sebagai upaya untuk memberikan gambarantentang bagaimana Implementasi Peraturan Daerah Nomor 06 Tahun 2008 Tentang Hygiene Sanitasi Tempat Pengelolaan Makanan, Minuman dan Tempat-Tempat Umum di Kota Palangka Raya. Tipe penelitian yang digunakan adalah metode penelitian kualitatif. Sumber data dalam penelitian ini terdiri dari data primer dan sekunder. Yang menjadi sumber data primer adalah Dinas Kesehatan Kota Palangka Raya dan Puskesmas se Kota Palangka Raya, Pemilik atau Penanggung Jawab TPM dan TTU dan Masyarakat Kota Palangka Raya sedangkan sumber datasekundernya adalah Peraturan Daerah Nomor 06 Tahun 2008. Teknik mengumpulkan data melalui Observasi, Wawancara dan Dokumentasi. Analisa data menggunakan prosedur analisis data kualitatif, yaitu reduksi data, penyajian data dan penarikan kesimpulan.

Berdasarkan hasil penelitian dapat dijelaskan bahwa Implementasi Peraturan Daerahtentang Hygiene Sanitasi Tempat Pengelolaan Makanan, Minuman dan Tempat-Tempat Umum di Kota Palangka Raya secara umum belum terealisasidengan baik, hal ini karena (I) Peengelola belum mengikuti peraturan yang ada (2) Meski sosialisasi berbentuk himbauan dan masukan sudah dilakukan tetapitidak memberikan kesadaran kepada pengelola untuk mematuhinya (3) Program IS(Inspeksi Sanitasi) belum optimal dilakukan.
\end{abstract}

\section{PENDAHULUAN}

Hygiene Sanitasi merupakan bagian penting dalam proses pengolahan pangan yang harus dilaksanakan dengan baik. Hygiene Sanitasi merupakan upaya untuk mengendalikan faktor orang, tempat dan perlengkapannya yang dapat atau mungkin dapat menimbulkan penyakit atau gangguan kesehatan. Proses produksi makanan dilakukan melalui serangkaian kegiatan yang meliputi persiapan, pengolahan dan penyajian makanan. Oleh karena itu, hygiene sanitasi dalam proses pengolahan pangan dilakukan sejak proses penanganan bahan mentah sampai produk makanan siap dikonsumsi. Hygiene Sanitasi meliputi kegiatan-kegiatan 
aseptic dalam persiapan, pengolahan dan penyajian makanan; pembersihan dan sanitasi lingkungan kerja; dan kesehatan pekerja.

Pemilik ataupun penanggung jawab dan masyarakat sepertinya tidak mengetahui adanya aturan tersebut dan mungkin saja tahu tapi mengabaikannya. Padahal seharusnya setiap Tempat Pengelolaan Makanan, Minuman dan Tempat-tempat Umum yang sudah disebutkan diatas wajib memenuhi Persyaratan Laik Hygiene Sanitasi dari Dinas Kesehatan. Seperti pada pasal 4 Peraturan Daerah Nomor 06 Tahun 2008 yang menyatakan Setiap Pengelola TPM dan TTU wajib memenuhi ketentuan persyaratan Laik Hygiene Sanitasi yang berlaku. Tidak adanya sanksi dan tindakan tegas dari Pemerintah Daerah Kota Palangka Raya terkait pelanggaran yang dilakukan oleh para pedagang di Lingkungan Kota Palangka Raya membuat Hygiene Sanitasi Tempat Pengelolaan Makanan, Minuman dan Tempat-tempat umum seolah belum terwujud dengan semestinya.

Lantas bagaimana komunikasi yang dilakukan oleh Pemerintah Daerah Kota Palangka Raya terhadap keberadaan Peraturan Daerah Nomor 06 Tahun 2008 kepada masyarakat Kota Palangka Raya dan juga seluruh stakeholders yang terlibat dalam pelaksanaan dan pengimplementasian kebijakan mengenai hygiene sanitasi pengelolaan makanan, minuman pada fasilitas umum. Hal inilah yang menjadi daya tarik penulis untuk meneliti mengenai Implementasi Kebijakan Hygiene Sanitasi Pengelolaan Makanan, Minuman Pada Fasilitas Umum di Kota Palangka Raya.

Implementasi adalah suatu tindakan atau pelaksanaan dari sebuah rencana yang sudah disusun secara matang dan terperinci. Berikut ini ada sedikit tentang pengertian menurut para ahli. Kamus Webster (Wahab, 2010:64) merumuskan secara pendek bahwa (mengimplementasikan) berarti menyediakan sarana untuk melaksanakan sesuatu; menimbulkan dampak/akibat terhadap sesuatu. Kemudian dalam artian sederhana implementasi dapat di pahami sebagai pelaksanaan atau kegiatan. Lebih lanjut menurut Hinggis (Pasolong, 2011:57) mendefinisikan “implementasi sebagai rangkuman dari berbagai kegiatan yang di dalamnya sumber daya manusia menggunakan sumber daya lain untuk mencapai sasaran strategi”.

Menurut Rippley dan Franklin (Tangkilisan,2003:2I-22) menyatakan keberhasilan implementasi kebijakan program dan ditinjau dari tiga faktor yaitu:

I. Prespektif kepatuhan (compliance) yang mengukur implementasi dari kepatuhan strate level burcancrats terhadap atas mereka.

2. Keberhasilan implementasi dapat diukur dari kelancaran rutinitas dan tiadanya persoalan

3. Implementasi yang berhasil mengarah kepada kinerja yang memuaskan semua pihak terutama kelompok penerima manfaat yang diharapkan.

Menurut Pendapat Sri Sukmainah (2011:8) mengatakan Hygiene adalah upaya kesehatan dengan cara memelihara dan melindungi kebersihan individu. Misalnya mencuci tangan, mencuci piring dan membuang bagian makanan yang rusak”. Higiene ini sebenarnya merujuk pada artian seluruh kondisi atau tindakan yang dilakukan guna meningkatkan kualitas kesehatan. Tindakan- tindakan tersebut meliputi tindakan pemeliharaan kesehatan, pencegahan penyakit, perawatan kesehatan dan mencakup juga perlindungan kesehatan akibat dari pekerjaan yang dilakukan oleh pengolah makanan, minuman. Kemudian Purnawijayanti (200I:2) mengatakan Sanitasi dapat didefenisikan sebagai usaha pencegahan penyakit dengan cara menghilangkan atau mengatur faktor-faktor lingkungan yang berkaitan dengan rantai perpindahan penyakit tersebut. 


\section{METODOLOGI}

Dalam hal ini, peneliti menggunakan penelitian kualitatif. Sebagaimana yang diungkapkan oleh Gunawan (2014:80), Penelitian kualitatif dimaksud sebagai jenis yang temuannya tidak diperoleh melalui prosedur statistic atau bentuk hitungan lainnya. Penelitian kualitatif dilakukan dalam situasi yang wajar (natural setting).

Dalam metode penelitia kualitatif lebih melihat fenomena sosial apa yang ada di masyarakat yang menarik untuk dilakukan penelitian. Metode kualitatif berusaha untuk memahami dan menafsirkan makna suatu peristiwa yang ada, interaksi tingkah laku manusia juga terkadang ada perspektif berdasarkan peneliti itu sendiri. Penelitian yang menggunakan penelitian kualitatif bertujuan untuk memahami objek yang diteliti secara mendalam.

Sehingga yang menjadi tujuan dari penelitian ini adalah ingin mengetahui realita dibalik suatu fenomena secara lebih mendalam, rinci dan tuntas. Oleh karena itu penggunaan metode kualitatif dalam penelitian ini adalah dengan mencocokkan realita yang ada dengan teori yang berlaku dengan menggunakan metode deskriptif.

\section{HASIL DAN PEMBAHASAN}

Dari hasil penelitian yang telah dilakukan, maka peneliti merasa ada beberapa hal yang perlu peneliti jelaskan terkait implementasi kebijakan pengelolaan makanan dan minuman pada fasilitas umum di Kota Palangka Raya ini dengan berdasarkan pada teori yang dipakai dalam penelitian ini, yaitu menggunakan teori Rippley dan Franklin (Tangkilisan,2003:2I-22) untuk mengukur keberhasilan implementasi yaitu, perspektif kepatuhan, rutinitas dan ketiadaan persoalan serta kinerja yang memuaskan semua pihak. Berdasarkan hasil penelitian tersebut maka dapat dijelaskan sebagai berikut :

a. Berdasarkan Prespektif Kepatuhan
Berdasarkan hasil penelitian, maka dapat dikatakan implementasi dapat berjalan dengan baik apabila prespektif kepatuhan dapat terpenuhi dengan baik pula. Dapat dikatakan patuh apabila para pelaksana aturan dan penerima aturan dapat menjalankan aturan dengan patuh serta penuh dengan rasa tanggung jawab terhadap aturan yang ada.

Terkait Kebijakan Hygiene Sanitasi Tempat Pengelolaan Makanan, Minuman pada fasilitas umum di Kota Palangka Raya ini sebenarnya sudah diatur dalam Peraturan Daerah Nomor 06 Tahun 2008 , isi dari Peraturan Daerah ini meliputi, diwajibkannya setiap Tempat Pengelolaan Makanan, Minuman dan TempatTempat Umum untuk memiliki Sertifikat Laik Hygiene Sanitasi dan untuk penjamah makanan diwajibkan memiliki Surat Keterangan Sehat yang keduanya harus selalu diperbaharui. Selain itu, dalam Peraturan Daerah ini juga jelas bahwa Dinas Kesehatan dan Puskesmas selaku implementor harus melakukan pengawasan dan pembinaan kepada setiap Tempat Pengelolaan Makanan, Minuman dan Tempat-Tempat Umum setiap 3 (tiga) bulansekali.

b. KelacaranRutinitasdanKetiadaanPersoalan

Keberhasilan implementasi ditandai dengan adanya kelancaran rutinitas dan ketiadaan persoalan atau tidak adanya masalah-masalah yang dihadapi. Implementasi dapat dikatakan berjalan dengan lancar apabila tidak ditemukannya masalah yang berarti dan program yang ada dapat direalisasikan sesuai dengan tujuan.

Berdasarkan hasil penelitian, dalam Peraturan Daerah Nomor 06 Tahun 2008 yang berkaitan dengan Hygiene Sanitasi Pengelolaan Makanan dan Minuman Pada Fasilitas Umum di Kota Palangka Raya diketahui bahwa Dinas Kesehatan Kota Palangka Raya serta Puskesmas 
selaku implementator telah memberikan himbuan- himbauan, teguran, serta masukan kepada para pemilik atau penanggung jawab usaha tetapi pada kenyataannya masih sedikit Tempat Pengelolaan Makanan, Minuman dan TempatTempat Umum yang bisa dikatakan memenuhi syarat Laik Hygiene Sanitasi.

Kebersihan tempat juga tidak pernah disoroti oleh pihak Dinas Kesehatan Kota Palangka Raya dan juga Puskesmas. Padahal kebanyakan tempat pengelolaan makanan, minuman di Kota Palangka Raya terbilang tidak memenuhi syarat hygiene sanitasi.

Sebagai salah satu contoh warungwarung jajanan dan makanan yang ada di bawah jembatan Kota Palangka Raya. Mendirikan bangunan tidak permanen di dekat selokan yang kotor dan berbau serta tidak menutup selokan air tersebut. Bahkan tempatmakanan diletakkan sangat berdekatan dengan selokan tersebut. Pembuangan limbah dan sampah disembarang tempat juga sudah menjadi pemandangan biasa yang terlihat di tempat pengelolaan makanan dan minuman tersebut. Masyarakat hanya tergiur dengan harga yang murah, pelayanan yang cepat dan rasa yang lumayan tanpa memikirkan aspek kelayakan dan kebersihan tempat dan makanan sertaminumannya.

Hal-hal seperti ini merupakan gambaran realita keadaan yang ada di Kota Palangka Raya, kebersihan akan makanan dan minuman serta tempat dan pengelolaannya tidak terlalu diperhatikan. Menunggu banyak kasus baru ada perhatian dan tindakan tetapi tidak disertai denan tindakan rutin seperti hal kecil yaitu melakukan pegawasan dan pembinaanrutin.

c. Keberhasilan Yang Memuaskan SemuaPihak

Berikutnya yang terakhir adalah bahwa keberhasilan implementasi mengarah kepada pelaksanaan dan dampaknya (manfaat) yang dikehendaki oleh semua pihak dari programprogram yang dilaksanakan.

Berdasarkan hasil penelitian, mengenai Implementasi Kebijakan Hygiene Sanitasi Pengelolaan Makanan dan Minuman Pada Fasilitas Umum di Kota Palangka Raya diketahui bahwa kegiatan atau program yang dilakukan oleh Dinas Kesehatan Kota Palangka Raya bersama dengan Puskesmas adalah IS (Inspeksi Sanitasi) yang menempatkan para sanitarian turun langsung ke lapangan untuk mengawasi dan membina pemilik atau penanggung jawab usaha masih dikatakan belum maksimal.

$\mathrm{Hal}$ ini terlihat dari hasil penelitian yang dilakukan oleh peneliti, yaitu dari 7 Puskesmas yang ada di Kota Palangka Raya diperoleh data TPM dan TTU sebanyak I.I54 yang tersebar di wilayah administrative Kota Palangka Raya. Dari jumlah I.I54 tersebut ternyata yang memiliki Sertifikat Laik Hygiene Sanitasi/Rekomendasi Kesehatan hanya berjumlah 20 saja. Dan peneliti juga tidak ada menemukan penjamah makanan yang memiliki surat keterangan sehat dari dokter.

Fakta yang ada ini cukup ironis mengingat Kota Palangka Raya merupakan Kota yang memiliki semboyan sebagai Kota CANTIK serta merupakan lbukota Provinsi Kalimantan Tengah yang juga direncanakan akan menjadi salah satu kandidat menjadi lbukota Negara Republik Indonesia. Di Kota Palangka Raya termasuk kota yang memiliki jumlah mahasiswa rantau yang cukup banyak.

Makanya saat ini kasus-kasus yang disebabkan makanan dan minuman terus meningkat, bukan hanya di Kota Palangka Raya tetapi tersebar hampir diseluruh Kabupaten di Provinsi Kalimantan Tengah. Sehingga ternyata sampai dengan saat ini program IS (Inspeksi Sanitasi) ternyata belum dapat menjawab semua persoalan yang terkait dengan hygiene sanitasi. 


\section{KESIMPULAN}

Berdasarkan hasil penelitian dan juga pembahasan dalam penelitian ini, maka dapat disimpulkan beberapa hal mengenai Implementasi Kebijakan Hygiene Sanitasi Pengelolaan Makanan dan Minuman Pada Fasilitas Umum di Kota Palangka Raya, secara umum dikatakan masih belum bisa terealisasi dengan baik, karena :

\section{Berdasarkan Prespektif Kepatuhan}

Dalam memberikan himbauan dan masukan kepada para pemilik maupun penanggung jawab usaha sehingga hanya sebagian yang mengetahui tentang Peraturan Daerah tersebut, itupun hanya sebatas tahu tetapi tidak mengetahui isinya secara rinci. Sehingga hal ini tidak dapat menumbuhkan kesadaran terhadap pemilik atau penanggung jawab usaha untuk mengikuti aturan yangditetapkan. Hal ini juga dikarenakan Dinas Kesehatan Kota Palangka Raya tidak bisa berlaku tegas terhadap para pemilik atau penanggung jawab usaha yang tidak mematuhi aturan.

2. Kelancaran Rutinitas dan Ketiadaan Persoalan Dinas Kesehatan Kota Palangka Raya serta Puskesmas selaku implementor telah memberikan himbuan-himbauan, teguran, serta masukan kepada para pemilik atau penanggung jawab usaha tetapi pada kenyataannya masih sedikit Tempat Pengelolaan Makanan, Minuman dan TempatTempat Umum yang bisa dikatakan memenuhi syarat Laik HygieneSanitasi.

3. Kinerja yang Memuaskan Semua Pihak

Bahwa kegiatan atau program yang dilakukan oleh Dinas Kesehatan Kota Palangka Raya bersama dengan Puskesmas adalah IS (Inspeksi Sanitasi) yang menempatkan para sanitarian turun langsung ke lapangan untuk mengawasi dan membina pemilik atau penanggung jawab usaha masih dikatakan belum maksimal.
Sehingga perlu Sosialisasi kepada pemilik atau penanggung jawab usaha ataupun kepada masyarakat Kota Palangka Raya, mengenai Peraturan Daerah Nomor 06 Tahun 2008 Tentang Hygiene Sanitasi Tempat Pengelolaan Makanan, Minuman dan TempatTempat Umum di Kota Palangka Raya dan menindak secara tegas para pemilik atau penanggung jawab usaha yang terbukti melanggar aturan. Dinas Kesehatan Kota Palangka Raya dan Puskesmas di wilayah kerja masingmasing perlu untuk lebih meningkatkan kerjasama dalam bidang pembinaan dan pengawasan minimal 3 bulan sekali. Serta Memaksimalkan pelaksanaan program IS (Inspeksi Sanitasi) pada pengelolaan makanan dan minuman pada fasilitas umum di Kota Palangka Raya.

\section{REFERENSI}

Abdul Wahab, Solichin. 2010. Analisis Kebijaksanaan dari Formulasi ke Implementasi Kebijaksanaan Negara, Jakarta: BumiAksara

Adik. 2014. Kesehatan Masyarakat di Indonesia, Jakarta: Raja Grafindo Persada

Afrizal. 20I4. Metode Penelitian Kualitatif.Jakarta:Raja Grafindo Persada

A.Purnawijayanti, Hiasinta. 200I. Sanitasi Higiene dan Keselamatan Kerja Dalam Pengolahan Makanan, Yogyakarta: Kanisius.

Gunawan, Imam. 20I4. Metode Penelitian Kualitatif, Teori danPraktik, Jakarta: Bumi Aksara

Hariyadi, Purwiyanto, dkk. 2009. Memproduksi Pangan Yang Aman, Jakarta: DianRakyat

Hessel Nogi S. Tangkilisan. 2003. Kebijakan Publik yang Membumi, Konsep, Strategi dan Kasus, Yogyakarta: Lukman Offset dan YPAPI 
Idrus, Muhammad, 2009, Metode Penelitian IImu Sosial, Yogyakarta: Erlangga

Moleong J. Lexy. 2012. Metodologi Penelitian Kualitatif, Bandung: PT. RemajaRosdakarya

Pasolong, Harbani. 20II. Teori Administrasi Publik. Bandung: Alfabeta

Peraturan Daerah Nomor 06 Tahun 2008 Tentang

Hygiene Sanitasi Tempat Pengelolaan Makanan,Minuman dan Tempat-tempatUmum.

Subirosa Sabarguna, Boy. 20II.Sanitasi Makanan dan Minuman Menuju Peningkatan Mutu Efesiensi Rumah Sakit, Jakarta: Salemba Medika.

Sugiyono. 2009. Metode Penelitian Kuantitatif, Kualitatif, $R \& D$, Bandung: Alfabeta Wibowo.

Winarno, Budi. 2007. KebijakanPublik, teori, dan proses, Jakarta: Media Pressindo

Yulianti, Nurheti. 2007. Awas! Bahaya Dibalik Lezatnya Makanan. Yogyakarta:CV.Andi Offset 